\title{
IMPULSO A LA IGUALDAD DE OPORTUNIDADES ENTRE HOMBRES Y MUJERES
}

Autora: Rosa María Iglesias Crespo.

Ediciones Paraninfo, Madrid, 2015.

Elisa Muñoz Catalán ${ }^{1}$

elisa.munoz@dthm.uhu.es

Universidad de Huelva

El necesario impulso que se le debe dar a la anhelada igualdad de género entre hombres y mujeres en nuestra sociedad actual, resulta objeto de análisis en la presente obra, a través de la cual, la profesora Iglesias Crespo nos adentra en la contextualización de las políticas de igualdad desde su fundamentación normativa a nivel internacional, comunitario, estatal y autonómico hasta una legislación como la presente que se encuentra marcada por la profunda crisis social, económica e incluso de valores que estamos sufriendo desde hace ya varios años; así como la misma analiza cuál es el alcance jurídico de las diferentes estrategias de promoción para la igualdad efectiva de mujeres y hombres, ya sea a través de medidas de acción positiva, estrategias como la "mainstreaming", o planes de igualdad de oportunidades.

Las premisas anteriores servirán para, en un segundo momento de la citada investigación, ahondar en la influencia real que han tenido durante décadas las situaciones de discriminación y desigualdad en los distintos ámbitos de desarrollo de la persona; determinando sus consecuencias jurídicas en esferas tan importantes hoy como pueden ser: el ámbito público/profesional, el personal/privado e, incluso, el doméstico. Lo que, sin duda, nos ayudará a comprender el necesario proceso de incorporación de la perspectiva de género en proyectos de intervención social, estableciendo su incidencia en la construcción del llamado "género" (roles, estereotipos, y valores en la igualdad de oportunidades).

$\mathrm{Y}$ es en este contexto en el que consideramos que tiene su razón de ser y fundamentación la recensión que presentamos, la cual, aborda el reciente trabajo publicado bajo el esperanzador título: Impulso a la igualdad de oportunidades entre hombres y mujeres, fruto de la necesidad de dar respuesta al Módulo Formativo transversal que lleva su misma denominación y que surge para dar cumplimiento a lo dispuesto en el Real Decreto 721/2011, de 20 de mayo, por el que se establecen cuatro certificados de profesionalidad de la familia profesional Servicios Socioculturales y a la Comunidad que se incluyen en el Repertorio Nacional de Certificados de Profesionalidad y se actualizan los

\footnotetext{
${ }^{1}$ Doctora en Derecho por la Universidad de Huelva, con Premio Extraordinario de Doctorado. Profesora acreditada de Derecho (Área: CCSS y Jurídicas) e Integrante del Grupo de Investigación (SEJ-460): El Derecho de Familia: Efectos Personales y Patrimoniales, de Roma al Derecho Actual.
} 
Certificados de Profesionalidad establecidos como Anexos I y II en el Real Decreto 1379/2008, de 1 de agosto.

Pues bien, dicho lo cual, en las siguientes líneas procedemos a detallar la estructura seguida en este proyecto sobre igualdad de género y no discriminación tan ambicioso. En primer término, cabe precisar que la premisa general de la que partimos es que el manual que estamos analizando respeta fielmente los contenidos y pautas marcadas por el antes mencionado Real Decreto 721/2011 y, en particular, en lo que concierne a los objetivos propuestos en el propio Módulo Formativo MF1026_3 rubricado, como se puede observar, de forma similar y con la denominación expresa de Impulso de la igualdad de oportunidades entre hombres y mujeres (MF1026_36). Tanto es así que los contenidos se desglosan en dos grandes Capítulos agrupados, a su vez, en diversos apartados y subapartados, que se van desarrollando de manera progresiva, a saber: 1. El primero, dedicado exclusivamente al Marco de intervención para el impulso de la igualdad efectiva de mujeres y hombres; 2. El segundo, por su parte, que abarca todo el El proceso de incorporación de la perspectiva de género en proyectos de intervención social.

Para acabar, finalmente, con un completo Glosario de términos que pueden ser consultados durante la lectura del presente trabajo y que, en todo caso, nos ayudarán a comprender muchos de los términos que hoy empleamos y cuyo alcance social o jurídico muchas veces no resulta comprensible de una mera lectura de los mismos; así como se incorpora un último epígrafe que nos da a conocer la reciente Bibliografía manejada en el desarrollo de este libro y que versa sobre políticas de igualdad, estrategias de promoción, o impulso e incorporación de la perspectiva de género a proyectos sociales surgidos en pro de la igualdad de género.

De este modo y, como se extrae de la propia Introducción a la obra, esa perspectiva de género se considera hoy el eje fundamental, en torno al cual, en el siglo XXI gira la mediación comunitaria y los intentos por incluir a las mujeres en las distintas estrategias, procedimientos y actuaciones que se lleven a cabo. No obstante lo anterior, en este punto, la investigadora no duda en recordarnos que:

“A pesar de las décadas de trabajo [...] la mujer sigue viviendo una discriminación camuflada en lo social, y es precisamente en esta esfera, desde la concepción misma de los proyectos de intervención social y apoyando a los profesionales que los elaboran y desarrollan, donde este manual puede resultar una ayuda inestimable" (Iglesias Crespo, 2015: 15)

Bajo las premisas expuestas centrémonos, pues, en el contenido del Capítulo 1 sobre El Marco de intervención para el impulso de la igualdad efectiva de mujeres y hombres. La idea general de la que se parte es que el concepto de "género" como tal surge en los años setenta en el contexto de la crítica feminista y en aras de tratar de explicar, desde una 
perspectiva novedosa, las diferencias entre ambos sexos y sobre las que, de alguna manera, se ha podido justificar la discriminación contra las mujeres a lo largo de la Historia. En este ámbito, se resalta cómo desde la primera Declaración Universal de Derechos Humanos (1789) muchos filósofos y pensadores, en general, han buscado justificar la exclusión de las mujeres de los derechos y de la ciudadanía, en base a una posible diferencia natural o biológica que asignaba a las mujeres una naturaleza distinta a la de los hombres, que parecía explicar sus menores capacidades para ser plenos sujetos de derecho y decidir sobre sus vidas, excluyéndolas del ámbito de lo público y de la política y, como mantiene la propia autora, en definitiva, las mujeres eran consideradas "seres inferiores"; de ahí que se constituyeran en sujetos dependientes y subordinados, siempre sometidos a tutela y vigilancia, y cuya principal función quedaría relegada a la reproducción y al ámbito del hogar y la familia.

Tras la perspectiva evolutiva de la teoría y de la historia de la construcción de género, se nos ofrece una interesante contextualización de esas políticas de igualdad, otorgando su fundamentación normativa a nivel no sólo autonómico o estatal, sino también comunitario e internacional. En este marco, no se duda en afirmar que las Comunidades Autónomas poseen un papel importante en la implementación de las políticas de igualdad en España; de hecho, de las 17 CCAA, la mayoría de éstas cuenta con un instituto para la igualdad, considerado como un organismo autónomo que promueve la igualdad de derechos y oportunidades entre mujeres y hombres, con el objeto no sólo de dar cumplimiento a lo dispuesto en el artículo 14 de la Constitución española de 1978 sino, también, de avanzar hacia un modelo de sociedad que incorpore nuevas formas de convivencia más democráticas y, por ende, más igualitarias. Para, en un segundo momento, establecer cuáles son esos organismos vinculados a la igualdad de género y no discriminación por razón de sexo.

Ello, en todo caso, conlleva a una valoración global de las estrategias de promoción vigentes en nuestro sistema jurídico, destacando:

a) De un lado las medidas de acción positiva previstas en nuestro ordenamiento jurídico, ya sean políticas (como la aplicación de la paridad a partir de un sistema de cuotas en el parlamento, gobierno, ayuntamiento, o dirección de empresas), económicas (subvenciones que favorezcan la contratación de mujeres en los espacios en los que no tienen la misma representación que los hombres), culturales o educativas (campañas de sensibilización de orientación no sexista o subvenciones para la investigación de los estudios de la mujer), legales (iniciativas judiciales para que no se discrimine a las mujeres o para prevenir esas situaciones de posible discriminación o violencia) e, igualmente, medidas sociales (tales como pueden ser, por ejemplo, la integración de minorías étnicas). 
b) De otro, la conocida como "mainstreaming" de género, es decir, aquella estrategia de la política de igualdad entre mujeres y hombres de la Unión Europea, que en España se conoce con el término de "transversalidad", y cuyos elementos clave son cinco: un concepto de igualdad de género más amplio, la incorporación de la perspectiva de género en la agenda política, la inclusión de la mujer en procesos de toma de decisiones, la prioridad dada a las políticas de igualdad de género, así como un cambio en las culturas institucional y organizativa.

c) Para, en último término, desarrollar el alcance legal de los planes de igualdad de oportunidades entre mujeres y hombres.

Y es aquí donde se alude a la influencia de las situaciones de discriminación y desigualdad en los diferentes ámbitos de desarrollo de la persona, ya sea en el ámbito público o profesional, en el personal o privado, y/o en el ámbito doméstico; hasta lograr el pretendido "empoderamiento" de la mujer, o lo que es lo mismo, un aumento de la participación de las mujeres en los procesos de toma de decisiones y acceso al poder (término acuñado en la Conferencia Mundial de las Mujeres de Beijing. Pekín, 1995) y que hoy se considera desde una perspectiva más amplia que abarca una dimensión de gran trascendencia, que no es otra, que la toma de conciencia del poder que individual y colectivamente ostentan las mujeres y que tiene que ver con la recuperación de la propia dignidad de las mujeres como personas.

Cambiando de tercio, el segundo Capítulo se encuentra ya íntegramente dedicado al Proceso de incorporación de la perspectiva de género en proyectos de intervención social. En él se analiza, de manera comparativa, cuál es la incidencia real en el proceso de socialización diferenciada y desigual para mujeres y hombres; ahondando, en primer lugar, en la construcción social del género, roles, estereotipos, y valores en la igualdad de oportunidades de género, así como en la aplicación de recursos lingüísticos para un uso no sexista ni androcéntrico del lenguaje, o aquellos otros recursos que reproduzcan imágenes y roles no sexistas en el tratamiento y representación de la mujer a través de las imágenes y los medios de comunicación; para, de esta forma, poder comprobar la efectiva influencia en el uso de tiempos y espacios igualitarios para mujeres y hombres (Iglesias Crespo, 2015: 93-119).

Lo anterior nos llevará, en último término, a destacar la incorporación de la perspectiva de género a los proyectos de intervención social, desde el diseño y adaptación de proyectos sociales surgidos en pro de la igualdad entre mujeres y hombres (Ibídem:120132); así como a la evaluación y seguimiento de las actuaciones y proyectos en ese impulso tan necesario de la igualdad real entre ambos sexos (Ibídem: 133-137), la identificación de los recursos y servicios de información, orientación, asesoramiento y formación (Ibídem: 138-144); ahondando en técnicas como el trabajo en equipo y las posibles vías de colaboración con personal técnico especializado en materia de igualdad efectiva entre 
mujeres y hombres (Ibídem: 145-148). Para acabar, finalmente, con el antes mencionado Glosario de términos y Bibliografía, ambos manejados a lo largo de la obra.

A modo de valoración global de la presente recensión, nos gustaría retomar el propio título del trabajo que hemos analizado, pues entendemos que el mismo nos ofrece una aproximación inicial y resumen al tema aquí tratado y, al mismo tiempo, nos incita a descubrir su contenido, que no es otro, que la importancia que hoy tiene el necesario: Impulso a la igualdad de oportunidades entre hombres y mujeres. En este sentido, consideramos que estamos ante un manual de gran alcance, que aborda la igualdad de género en tiempos de crisis como el actual, y que nos ofrece una contextualización reciente de las políticas de igualdad, una valoración de las estrategias de promoción basada en las diversas medidas de acción positiva, la transversalidad, y los planes de igualdad de oportunidades entre mujeres y hombres. Lo que favorece, sin duda, una progresiva incorporación de la perspectiva de género a los proyectos de intervención social, en los términos previamente reseñados.

\section{BIBLIOGRAFÍA}

- Iglesias Crespo, Rosa María (2015): Impulso a la igualdad de oportunidades entre hombres y mujeres. Madrid: Paraninfo. 